\title{
MANEJO DE CONTROLE DE PATÓGENOS DURANTE O DESENVOLVIMENTO E NA PÓS-COLHEITA DE FRUTOS DE PESSEGUEIRO
}

\author{
Daniele Cristina Fontana ${ }^{1 *}$, Stela Maris Kulczynski ${ }^{2}$, Renato $\operatorname{Trevisan}^{3}$, Marcos Vinícius \\ Marques Pinheiro ${ }^{4}$, Maria Inês Diel ${ }^{5}$, Matheus Otero Pinheiro ${ }^{6}$
}

1 Mestranda em Agronomia, Programa de Pós graduação em Agronomia, Agricultura e Ambiente, Universidade Federal de Santa Maria, Campus Frederico Westphalen/RS, Brasil. *E-mail: daani_fontana@hotmail.com

${ }^{2}$ Professora Dr ${ }^{a}$, Universidade Federal de Santa Maria, Campus Frederico Westphalen/RS, Brasil.

${ }^{3}$ Professor Dr ${ }^{\circ}$, Colégio Politécnico, Universidade Federal de Santa Maria, Campus Santa Maria/RS, Brasil.

${ }^{4}$ Pós doutorando, Programa de Pós graduação em Agronomia, Agricultura e Ambiente, Universidade Federal de Santa Maria, Campus Frederico Westphalen/RS, Brasil.

${ }^{5}$ Doutoranda em Agronomia, Universidade Federal de Santa Maria, Campus Santa Maria/RS, Brasil.

${ }^{6}$ Graduando em Agronomia, Universidade Federal de Santa Maria, Campus Frederico Westphalen/RS, Brasil.

RESUMO: O objetivo deste trabalho foi avaliar a aplicação de produtos naturais e químicos no controle de patógenos durante o desenvolvimento e na pós-colheita de frutos de pessegueiro, cultivar 'Precocinho', no ano de 2014. Para o primeiro experimento, avaliou-se em DBC 6x5 a eficiência de seis tratamentos [T1 - extrato de inflorescências de cravo da índia (CR); T2 - extrato de canela em casca (CA); T3 - extrato de folhas de boldo (BO); T4 fosfito de potássio (FP) $/ 2,0 \mathrm{ml} \mathrm{L}^{-1}$; T5 - fungicida tebuconazole (FT) $/ 1,0 \mathrm{ml} \mathrm{L}^{-1} \mathrm{e}$ T6 Controle (sem aplicação) (CO)] durante cinco épocas de desenvolvimento dos frutos, através da incidência de patógenos e sua correlação. No segundo experimento avaliou-se em DIC $6 \times 3$ o efeito das aplicações pré-colheita dos tratamentos acima citados, na pós-colheita dos frutos, quando submetidos a três períodos de armazenamento [0 dias (período 1); 7 dias de câmara fria (período 2); 7 dias de câmara fria a $2{ }^{\circ} \mathrm{C}+5$ dias de bancada a $23^{\circ} \mathrm{C}$ (período 3)], avaliou-se as características físicas, físico-químicas e fitossanitárias dos frutos. Os produtos naturais (extratos vegetais de canela, cravo e boldo) não apresentam influência positiva sobre fungos patogênicos durante a pré e pós-colheita do pessegueiro. Os aspectos qualitativos de frutos de pessegueiro cv. Precocinho, não são afetados pelos tratamentos naturais e químicos, na pós-colheita. As aplicações de fosfito de potássio nas plantas de pessegueiro não apresentaram resultados significativos para o controle de Monilinia fructicola na pré e na pós-colheita. $\mathrm{O}$ tratamento químico com tebuconazole apresenta controle eficiente da podridão parda. Os tratamentos naturais devem ser analisados a longo prazo, sugerindo-se novos estudos.

Palavras-chave: Monilinia fructicola. Prunus persica. Tebuconazole. Controle alternativo.

\section{MANAGEMENT OF PATHOGENS CONTROL DURING DEVELOPMENT AND POST-HARVESTING OF PEASANT FRUIT}

Cultura Agronômica, Ilha Solteira, v.27, n.1, p.124-140, 2018 


\begin{abstract}
The objective of this work was to evaluate the application of natural and chemical products in the control of pathogens during the development and post-harvest of peach fruits, 'Precocinho' cultivar, in the year 2014. For the first experiment, it was evaluated in DBC 6x5 the efficiency of six treatments [T1 - clove inflorescence extract (CR); T2 - cinnamon bark extract (CA); T3 - boldo leaf extract (BO); T4 - potassium phosphite (PF) / $2.0 \mathrm{ml} \mathrm{L}^{-1}$; T5 - fungicide tebuconazole (FT) / $1.0 \mathrm{ml} \mathrm{L} \mathrm{L}^{-1}$ and $\mathrm{T} 6$ - Control (without application) (CO)] during five periods of fruit development, through the incidence of pathogens and their correlation. In the second experiment, the effect of the pre-harvest applications of the aforementioned treatments on fruit post-harvest, when submitted to three storage periods [0 days (period 1), was evaluated in 6x3 ICD; 7 days cold chamber (period 2); 7 days of cold chamber at $2{ }^{\circ} \mathrm{C}+5$ days of bench at $23{ }^{\circ} \mathrm{C}$ (period 3)], the physical, physicochemical and phytosanitary characteristics of the fruits were evaluated. The natural products (plant extracts of cinnamon, clove and boldo) do not present positive influence on pathogenic fungi during the pre and post-harvest of the peach tree. The qualitative aspects of peach fruits cv. Precocinho, were not affected by the natural and chemical treatments, in the postharvest. The applications of potassium phosphite in the peach plants did not present significant results for the control of Monilinia fructicola in pre and post-harvest. The chemical treatment with tebuconazole showed efficient control of brown rot. Natural treatments should be analyzed in the long term, suggesting new studies.
\end{abstract}

Key words: Monilinia fructicola. Prunus persica. Tebuconazole. Alternate control.

\title{
INTRODUÇÃO
}

Os frutos de pessegueiro apresentam elevada perecibilidade, e diante disso, estão sujeitos a danos mecânicos e problemas fitossanitários como pragas e doenças, os quais podem afetar sua conservação, necessitando ser rapidamente armazenados ou comercializados (KESKE et al., 2011). A incidência de patógenos varia de acordo com as épocas de desenvolvimento dos frutos e as condições de armazenamento, aspectos importantes para identificar o momento ideal de controle. A principal doença que ataca os frutos de pessegueiro é ocasionada por Monilinia fructicola (Wint) Honey (MAY-DE MIO et al., 2008) contudo, outros patógenos como Rhizopus stolonifer (Ehrenb.) Vuill (MARTINS et al., 2005), Colletotrichum spp. (TOZZE JÚNIOR et al., 2015) podem ocasionar elevadas perdas na produtividade (CAI et al., 2015).

As perdas pós-colheita são ocasionadas principalmente por fungos e podem chegar a cerca de 50\%, ocasionando vários danos às frutas, como elevada desidratação, perda de firmeza de polpa, podridões pós-colheita (CAI et al., 2015), dentre outros. Para isso, o uso de fungicidas é o método de controle mais adotado nas regiões produtoras de pêssego (MAY-DE MIO et al., 2004). Normalmente, a tentativa de controle da podridão parda, causada pela Monilinia fructicola, depende de várias pulverizações com fungicidas curativos, as quais devem ser intensificadas na floração e pré-colheita dos frutos (MAY-DE 
MIO et al., 2008). Devido ao risco potencial dos fungicidas sintéticos para o ambiente e a saúde humana (CASALS et al., 2012) e a busca por frutos de qualidade, utilizando menores quantidades de defensivos, têm-se utilizado estratégias como: o sistema de produção integrada de frutas (COELHO et al., 2008), armazenamento refrigerado (SPADONI et al., 2013), controle biológico (BETTIOL, 1991), uso de fosfitos (OGOSHI et al., 2013) e produtos alternativos, como: extratos vegetais (VENTUROSO et al., 2011), óleos essenciais (SIVAKUMAR e BAUTISTA-BAÑOS, 2014), dentre outros.

O extrato bruto de algumas plantas tem indicado elevado potencial no controle de fitopatógenos, devido sua ação fungitóxica direta, inibindo o crescimento micelial e germinação de esporos (LINS et al., 2011). Dentre estes, destaca-se o extrato de cravo-daíndia (Caryophillus aromaticus L.) que atuam impedindo o desenvolvimento micelial de fungos como Rhizopus sp., Penicillium spp. e Aspergillus niger van Tieghem. (CHALFOUN et al., 2004) e de canela (Cinnamomum zaylanicum (Blume) que apresentam resultados positivos no controle de Cercospora kikuchii (Matsumoto \& Tomoy), Fusarium sp., Colletotrichum sp. e Phomopsis sp. (VENTUROSO et al., 2011). Além da utilização de extratos de plantas como alternativas para o manejo vêm sendo empregados fosfitos, apresentando efeito antifúngico direto e induzindo produção de fitoalexinas para proteção vegetal (OGOSHI et al., 2013) conforme constatado em diversos trabalhos (ARAÚJO et al., 2008; DANNER et al., 2008; MAZARO et al., 2008). Com o objetivo de reduzir o desenvolvimento de infecções latentes, o armazenamento refrigerado também constitui uma forma eficiente no atraso do desenvolvimento de doenças em frutas (LURIE e CRISOTO, 2005), sendo grandemente empregado na pós-colheita do pessegueiro.

A maioria dos trabalhos realiza avaliação de doenças apenas na colheita e pós-colheita dos frutos, apresentando elevada incidência de doenças, pois as infecções latentes são ativadas na maturação, durante a pós-colheita ou senescência dos frutos. Contudo, torna-se importante a análise da incidência dos patógenos presentes durante o desenvolvimento dos frutos, na busca pelo controle antecipado das doenças que acometem a cultura. Dessa forma, o objetivo deste trabalho foi avaliar o potencial de produtos naturais e químicos no controle de patógenos durante o desenvolvimento e na pós-colheita de frutos de pessegueiro da cultivar 'Precocinho'.

\section{MATERIAL E MÉTODOS}

\section{Local e condições do experimento}

O experimento foi desenvolvido na Universidade Federal de Santa Maria, Campus Frederico Westphalen, e executado em pomar comercial da cidade de Planalto - RS, sendo dividido em duas etapas: pré-colheita e pós-colheita de pêssegos da cultivar 'Precocinho'. O delineamento utilizado à campo foi blocos casualizados (DBC), e cada bloco composto por três plantas espaçadas $3 \times 2 \mathrm{~m}$, com três repetições, totalizando em nove unidades experimentais. Sendo composta por plantas com dez anos de idade da safra de 2014/2015. 


\section{Experimento 1 - Produtos naturais e químicos no controle de patógenos durante o desenvolvimento de frutos de pessegueiro}

A pulverização de soluções alternativas em plantas de pessegueiro iniciou a partir da floração da cultura (30 de julho de 2014) com intervalo de 15 dias. Concomitante aos intervalos da pulverização procedeu-se a coleta de frutos até o período da colheita (15 de outubro de 2014), totalizando cinco épocas de coleta, caracterizando cinco épocas de desenvolvimento dos frutos.

Dessa forma, o experimento foi conduzido em DBC, esquema fatorial 6x5, sendo seis tratamentos [T1 - extrato de inflorescências de cravo da índia (CR); T2 - extrato de canela em casca (CA); T3 - extrato de folhas de boldo (BO); T4 - fosfito de potássio (FP) /2,0 ml $\mathrm{L}^{-1}$; T5 - fungicida tebuconazole (FT) /1,0 ml L-1; T6 - controle (sem aplicação) (CO)] e cinco épocas de desenvolvimento dos frutos $[0 ; 33 ; 48 ; 63$ e 84 dias após florescimento (DAF)], totalizando 30 tratamentos, com três repetições/tratamento e a unidade experimental composta por 10 frutos. Os extratos foram preparados na forma de infusão, através da imersão do material vegetal em água quente, permanecendo até o resfriamento da solução. Os extratos foram pulverizados na concentração de $10 \%$ do extrato bruto (EB).

Os frutos coletados foram encaminhados ao Laboratório de Fitopatologia - UFSM, e realizada a desinfestação a partir da imersão dos mesmos durante um minuto em solução de álcool $70 \%$, hipoclorito de sódio a $1 \%$, e posteriormente lavados em água esterilizada. Em seguida, foram dispostos em câmara úmida em embalagens plásticas, e armazenados durante dez dias em câmara do tipo BOD a $25^{\circ} \mathrm{C}$ e fotoperíodo de 12 horas.

Após este período os frutos foram avaliados individualmente em lupa estereoscópica para a variável incidência de patógenos. Caracterizou-se a incidência pela porcentagem (\%) de frutos com infecções e com estruturas de patógenos em sua superfície, os quais foram identificados com auxílio de bibliografias correspondentes.

Os dados foram submetidos à análise de variância, e as médias dos tratamentos comparadas pelo teste de Tukey, a 5\% de probabilidade, por meio do programa estatístico Genes (CRUZ, 2013).

\section{Experimento 2 - Produtos naturais e químicos no controle de patógenos na pós- colheita de frutos de pessegueiro}

A execução do experimento de pós-colheita foi realizada quando os frutos de pessegueiro, oriundos das aplicações dos tratamentos de pré-colheita chegaram ao estádio de maturação fisiológica (84 DAF), foram coletados e levados ao Laboratório de Fitopatologia da UFSM. O delineamento foi inteiramente casualizado (DIC), com esquema fatorial 6x3, sendo seis tratamentos [T1 - extrato de inflorescências de cravo da índia (CI); T2 - extrato de canela em casca (CA); T3 - extrato de folhas de boldo (BO); T4 - fosfito de potássio (FP)/2,0 ml L-1; T5 - fungicida tebuconazole (FT)/1,0 $\mathrm{ml} \mathrm{L}^{-1}$; T6 - controle (sem aplicação) (CO)], e três períodos de armazenamento [0 dias (período 1); 7 dias de câmara 
fria (período 2); 7 dias de câmara fria a $2^{\circ} \mathrm{C}+5$ dias de bancada a $23^{\circ} \mathrm{C}$ (período 3)], totalizando 18 tratamentos, cada um com três repetições, e cada repetição composta por cinco frutos. Os frutos foram dispostos em bandejas desinfestadas sob suportes plásticos individuais (PVC) e armazenados.

No final de cada período de armazenamento procedeu-se avaliações das características físicas [diâmetro médio $(\mathrm{mm})$; altura $(\mathrm{mm})$; e massa fresca $(\mathrm{g})$ ], físico-químicos dos frutos [textura $(\mathrm{N})$, com auxílio de um penetrômetro; e sólidos solúveis, determinados por refratometria e expressos em graus Brix ( ${ }^{\circ}$ Brix)], incidência (porcentagem de frutos infectados); e severidade de Monilinia fructicola (análise visual da porcentagem de doença/ fruto).

Os resultados obtidos foram submetidos à análise de variância e as médias comparadas pelo teste de Tukey a 5\% de probabilidade, pelo programa estatístico Genes (CRUZ, 2013). Por não seguir a distribuição normal pelo teste de Shapiro-Wilk $(\alpha=0,05)$, os dados das variáveis altura $(\mathrm{mm})$, largura $(\mathrm{mm})$, massa fresca $\left(\mathrm{g}\right.$ fruto $\left.{ }^{-1}\right), \mathrm{SST}\left({ }^{\circ}\right.$ Brix $)$, textura $(\mathrm{N})$, incidência e severidade de Monilinia fructicola (\%), foram transformados para $\sqrt{x+0,5}$.

\section{RESULTADOS E DISCUSSÕES}

\section{Experimento 1 - Produtos naturais e químicos no controle de patógenos durante o desenvolvimento de frutos de pessegueiro}

A análise de variância revelou efeito significativo na incidência dos patógenos apenas para o fator épocas de desenvolvimento dos frutos, pelo teste $\mathrm{F}(\mathrm{p}<0,05)$. Durante o desenvolvimento de frutos de pessegueiro cv. Precocinho verificou-se a incidência de vários patógenos, porém, apenas oito mostraram-se significativos, sendo estes Monilinia fructicola, Colletotrichum spp., Cladosporium spp., Alternaria spp., Penicillium spp., Epicocum spp. e Torula spp. (Figura 1).

Os patógenos Monilinia fructicola, Colletotrichum spp. e Penicillium spp. aumentaram sua incidência nos frutos no transcorrer das épocas de avaliação, e sua maior incidência foi verificada na época $84 \mathrm{DAF}$, diferindo estatisticamente das demais. No entanto, alguns patógenos como Epicocum spp. e Torula spp. apresentaram superioridade estatística nas épocas de desenvolvimento referentes a 48 e 63 DAF. A maior incidência de Alternaria spp. ocorreu aos $48 \mathrm{DAF}$, com aproximadamente $26 \%$, sendo superior às demais épocas (Figura 1). 


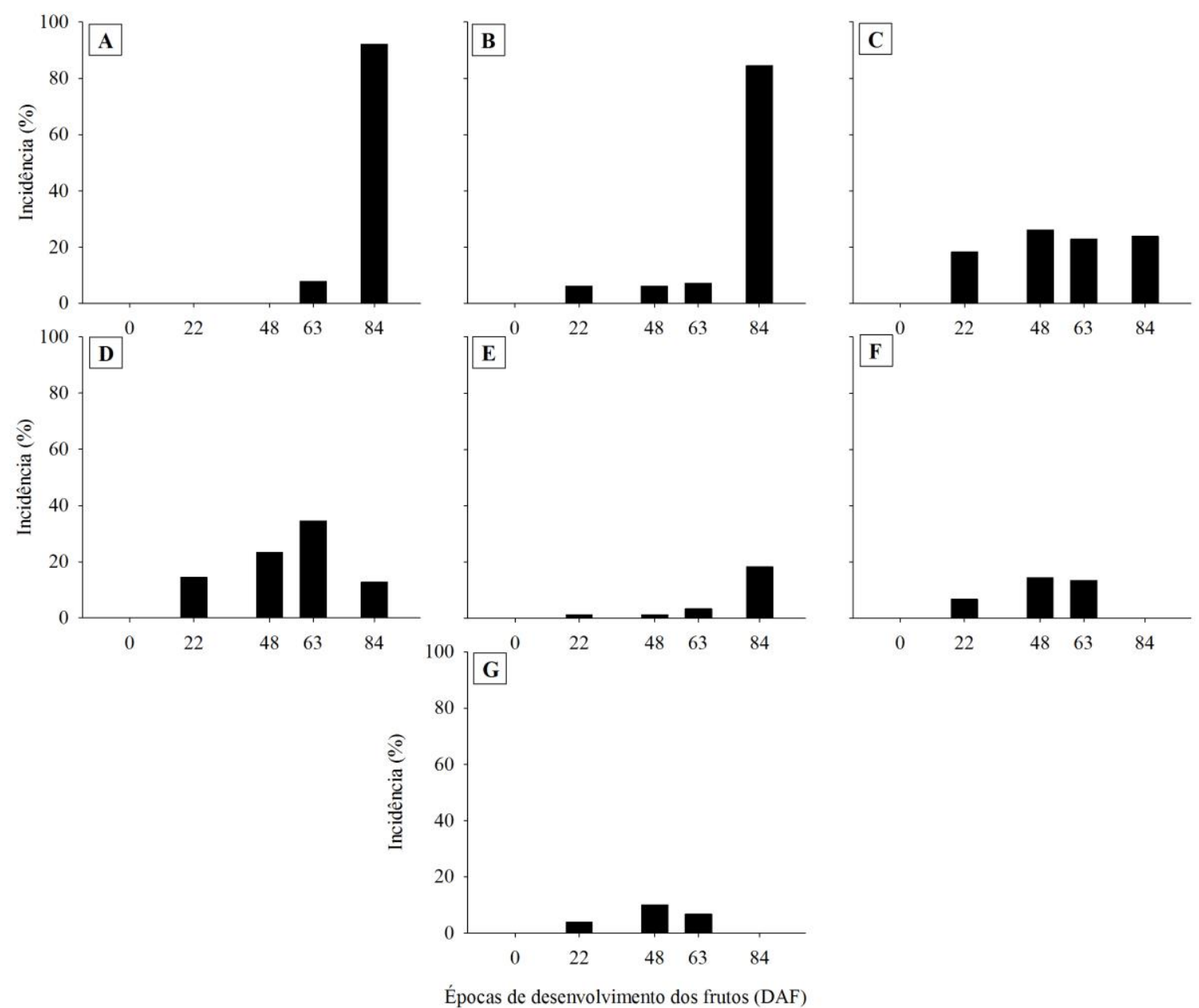

Figura 1. Incidência de patógenos durante épocas de desenvolvimento dos frutos de pessegueiro, submetidos aos tratamentos alternativos de cravo da índia (CR), canela em casca (CA), folhas de boldo (BO), fosfito de potássio (FP), fungicida tebuconazole (FT) e controle (CO), avaliados em dias após florescimento (DAF), na pré-colheita, sendo: (A) Monilinia fructicola, (B) Colletotrichum spp., (C) Cladosporium spp., (D) Alternaria spp., (E) Penicillium spp. (F) Epicocum spp. (G) Torula spp. Frederico Westphalen, RS, 2017.

\section{Experimento 2 - Produtos naturais e químicos no controle de patógenos na pós- colheita de frutos de pessegueiro}

Para a variável incidência de Monilinia fructicola houve significância apenas para o fator tratamentos (Figura 2), e para as características físicas (altura, largura e peso) houve significância, pelo teste $\mathrm{F}$, para o fator períodos de armazenamento (Tabela 1). A análise de variância revelou interação significativa para tratamentos $\mathrm{x}$ períodos de armazenamento para a variável severidade de Monilinia fructicola (Tabela 2).

Os tratamentos aplicados não influenciaram, de forma significativa, as características de qualidade na pós-colheita dos frutos (dados não apresentados). Os períodos de 
armazenamento diferiram significativamente entre si, ocasionando redução das médias das variáveis altura, largura e peso, sendo verificadas as menores médias no período 3. A textura (N) dos frutos de pessegueiro mantiveram-se semelhantes desde o tempo zero, que corresponde ao ponto de colheita (período 1), até o período 2 de armazenamento, com sete dias de câmara fria. Diferenças significativas foram encontradas no último período de armazenamento (período 3), apresentando os menores valores de textura, com 2,96 N. Para a variável sólidos solúveis totais (STT) os três períodos de armazenamento apresentaram diferenças significativas entre si, sendo reduzidas no período 2 e aumentando no período 3 , com 6,54 e 11,27 ${ }^{\circ}$ Brix, respectivamente (Tabela 1).

Tabela 1. Altura (AL), largura (LG) e massa fresca (MF), sólidos solúveis totais (SST), textura (T), incidência (INC) e severidade (SEV), de frutos de pessegueiro submetidos a tratamentos alternativos de cravo da índia (CR), canela em casca (CA), folhas de boldo (BO), fosfito de potássio (FP), fungicida tebuconazole (FT) e controle (CO) na pré-colheita, sob períodos de armazenamento [0 dias (período 1); 7 dias de câmara fria (período 2); 7 dias de câmara fria a $2^{\circ} \mathrm{C}+5$ dias de bancada a $23^{\circ} \mathrm{C}$ (período 3)], Frederico Westphalen, 2017.

\begin{tabular}{cccccccc}
\hline Período & $\begin{array}{c}\mathrm{AL} \\
(\mathrm{mm})\end{array}$ & $\begin{array}{c}\mathrm{LG} \\
(\mathrm{mm})\end{array}$ & $\begin{array}{c}\text { MF } \\
\left(\mathrm{g} \mathrm{fruto}^{-1}\right)\end{array}$ & $\begin{array}{c}\text { STT } \\
\left({ }^{\circ} \mathrm{Brix}\right)\end{array}$ & $\begin{array}{c}\mathrm{T} \\
(\mathrm{N})\end{array}$ & $\begin{array}{c}\text { INC } \\
(\%)\end{array}$ & $\begin{array}{c}\text { SEV } \\
(\%)\end{array}$ \\
\hline Período 1 & $52,25 \mathrm{a}^{*}$ & $48,91 \mathrm{a}$ & $58,56 \mathrm{a}$ & $8,46 \mathrm{~b}$ & $6,08 \mathrm{a}$ & $0,00 \mathrm{c}$ & $0,00 \mathrm{~b}$ \\
Período 2 & $46,53 \mathrm{~b}$ & $43,13 \mathrm{~b}$ & $45,44 \mathrm{~b}$ & $6,54 \mathrm{c}$ & $6,11 \mathrm{a}$ & $18,88 \mathrm{~b}$ & $0,00 \mathrm{~b}$ \\
Período 3 & $38,31 \mathrm{c}$ & $33,44 \mathrm{c}$ & $29,76 \mathrm{c}$ & $11,27 \mathrm{a}$ & $2,69 \mathrm{~b}$ & $85,55 \mathrm{a}$ & $66,52 \mathrm{a}$ \\
\hline CV (\%) & 2,40 & 3,12 & 6,85 & 12,05 & 10,22 & 35,77 & 43,56 \\
\hline
\end{tabular}

*Médias seguidas das mesmas letras minúsculas na coluna não diferem estatisticamente entre si, pelo teste de Tukey a $5 \%$ de probabilidade. Dados transformados por Raiz quadrada de $\mathrm{Y}+0.5-\mathrm{SQRT}(\mathrm{Y}+0.5)$, médias originais.

Os tratamentos aplicados na pré-colheita influenciaram significativamente a incidência e a severidade de Monilinia fructicola na pós-colheita de frutos de pessegueiro. Os menores valores foram verificados no tratamento com fungicida tebuconazol (FT), atingindo $80 \%$ de controle, diferindo estatisticamente apenas da aplicação com extrato de CR, com 48,8\% de incidência. Embora em menores proporções, os extratos vegetais de canela em casca (CA), boldo (BO) e fosfito de potássio (FP) apresentaram 68,89, 62,23 e $60 \%$ de controle da incidência, respectivamente (Figura 2). 


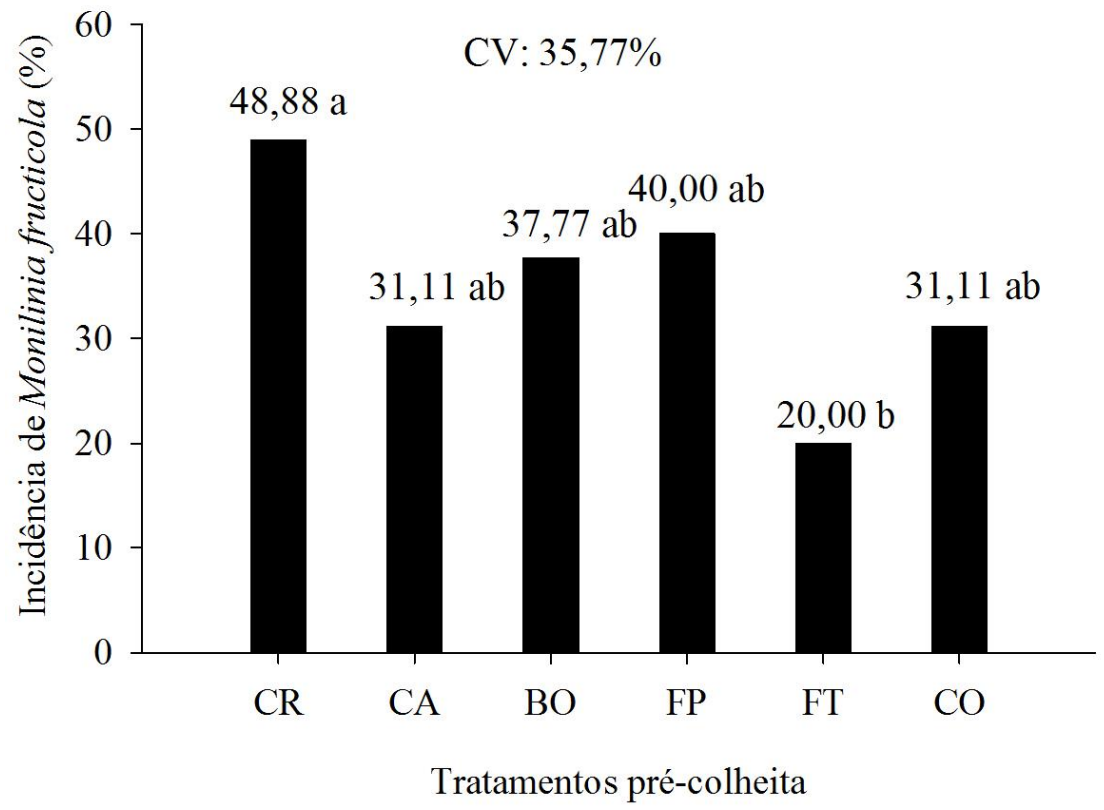

*Médias seguidas pela mesma letra minúscula não diferem estatisticamente entre si, pelo teste de Tukey a 5\% de probabilidade. Dados transformados por raiz quadrada de $\mathrm{Y}+0.5$ - SQRT $(\mathrm{Y}+0.5)$, médias originais.

Figura 2. Incidência de Monilinia fructicola na pós-colheita de frutos de pessegueiro cv. Precocinho, submetidos aos tratamentos alternativos de cravo da índia (CR), canela em casca (CA), folhas de boldo (BO), fosfito de potássio (FP), fungicida tebuconazole (FT) e controle (CO) na pré-colheita. Frederico Westphalen, RS, 2017.

Tabela 2. Severidade de Monilinia fructicola (\%) em frutos de pessegueiro submetidos aos tratamentos alternativos de cravo da índia (CR), canela em casca (CA), folhas de boldo (BO), fosfito de potássio (FP), fungicida tebuconazole (FT) e controle (CO) durante a précolheita, sob diferentes períodos de armazenamento: [0 dias (período 1); 7 dias de câmara fria (período 2); 7 dias de câmara fria a $2^{\circ} \mathrm{C}+5$ dias de bancada a $23^{\circ} \mathrm{C}$ (período 3)], Frederico Westphalen, 2017.

\begin{tabular}{cccc}
\hline \multirow{2}{*}{ Tratamentos } & \multicolumn{3}{c}{ Severidade de Monilinia fructicola $(\%)$} \\
\cline { 2 - 4 } & Período 1 & Período 2 & Período 3 \\
\hline CR & $0,0 \mathrm{aB} *$ & $0,0 \mathrm{aB}$ & $87,6 \mathrm{aA}$ \\
CA & $0,0 \mathrm{aB}$ & $0,0 \mathrm{aB}$ & $76,0 \mathrm{aA}$ \\
$\mathrm{BO}$ & $0,0 \mathrm{aB}$ & $0,0 \mathrm{aB}$ & $83,6 \mathrm{aA}$ \\
FP & $0,0 \mathrm{aB}$ & $0,0 \mathrm{aB}$ & $66,0 \mathrm{aA}$ \\
FT & $0,0 \mathrm{aB}$ & $0,0 \mathrm{aB}$ & $24,1 \mathrm{bA}$ \\
$\mathrm{CO}$ & $0,0 \mathrm{aB}$ & $0,0 \mathrm{aB}$ & $61,6 \mathrm{aA}$ \\
\hline $\mathrm{CV}$ & & $20,96 \%$
\end{tabular}

*Médias seguidas pela mesma letra minúscula não diferem estatisticamente entre si, pelo teste de Tukey a 5\% de probabilidade. Dados transformados por Raiz quadrada de $\mathrm{Y}+0.5-\mathrm{SQRT}(\mathrm{Y}+0.5)$, médias originais.

Cultura Agronômica, Ilha Solteira, v.27, n.1, p.124-140, 2018 
A severidade de Monilinia fructicola foi nula no tempo zero (período 1) e no segundo período de armazenamento, representando o período 1 e 2, contudo, no período 3 houve grande incidência, diferindo estatisticamente dos demais períodos. O FT apresentou 37,5\% de controle da severidade de podridão parda (em relação ao controle), diferindo significativamente dos demais tratamentos (Tabela 2).

As infecções por fungos durante o florescimento podem levar à morte das flores ou mesmo manter o fungo latente durante a formação dos frutos (KESKE et al., 2011; MAYDE MIO et al., 2008). Durante a colheita e pós-colheita, os frutos de pêssego estão sujeitos a danos mecânicos e, podem proporcionar porta de entrada de diversos problemas fitossanitários (KESKE et al., 2011). Diante disso, a diagnose de infecções latentes na précolheita, conforme realizado neste trabalho, auxilia o produtor a adequar seu planejamento no controle de doenças durante a floração, corroborando com os resultados encontrados por May-de Mio (2008) e Moreira e May-de Mio (2009).

A maior incidência de fungos fitopatogênicos foi observada durante o período de colheita dos frutos de pessegueiro. Durante este período, os tecidos dos frutos tornam-se mais suscetíveis à incidência de doenças, devido às infecções latentes tornarem-se ativas, expressando-se com maior intensidade. A suscetibilidade dos frutos de pessegueiro à infecção por podridão parda torna-se fortemente relacionada ao estádio de desenvolvimento dos frutos, e às características de cada cultivar (LEE e BOSTOCK, 2007). De modo geral, frutos imaturos são mais resistentes à infecção por Monilinia fructicola, pois apresentam elevadas concentrações de ácido clorogênico (VILLARINO et al., 2011), um composto antioxidante presente no endocarpo dos frutos, sendo produzido por plantas em resposta às condições de estresse, como infecções por patógenos ou danos mecânicos (FATTOUCH et al., 2008).

Oscilações das concentrações do ácido clorogênico, durante a maturação dos frutos de pessegueiro, podem explicar, no presente trabalho, a baixa ocorrência de doenças identificada nos primeiros estádios de desenvolvimento dos frutos, e a maior patogenicidade dos fungos, como Monilinia fructicola e Colletotrichum spp. $(92,22 \%$ e $84,44 \%$ de incidência, respectivamente) no período de colheita, quando a concentração deste ácido é reduzida.

Devido á característica climatérica do pessegueiro, os frutos apresentam elevada perecibilidade na pós-colheita, rápida perda da textura, incidência de podridões e murchamento (NAVA e BRACKMANN, 2001). Durante este período, os frutos apresentam tendência de estabilizar suas trocas gasosas, devido principalmente, à transpiração e a perda de água durante o período de armazenamento (MAGUIRE et al., 2000). Outra característica importante do armazenamento de pêssegos é a desidratação natural e desmontagem de polissacarídeos da parede celular (VICENTE et al., 2007), que proporciona redução da textura, justificando, dessa forma, a redução do tamanho dos frutos e perda de água verificadas neste experimento.

Cultura Agronômica, Ilha Solteira, v.27, n.1, p.124-140, 2018 
A redução do teor de SST ( ${ }^{\circ}$ Brix) ocorreu devido à transpiração acelerada logo após à colheita, com posterior degradação das paredes celulares, o que reduziu a textura para menos de $10 \mathrm{~N}$ aos 7 dias de armazenamento refrigerado $\left(-0,5^{\circ} \mathrm{C}\right)$ (Tabela 1$)$. Condições de ambiente refrigerado, seguido da exposição dos frutos à temperatura ambiente, tende a restabelecer a suculência dos frutos, aumentando assim, o teor de açúcares e diminuindo sua firmeza (NAVA e BRACKMANN, 2001), confirmando os resultados obtidos neste estudo. Assim, a refrigeração auxilia na manutenção das características físicas dos frutos e mantém a sanidade, atrasando os sintomas em frutos já contaminados (MOREIRA e MAY-DE MIO, 2009), prolongando o tempo de incubação (ZHANG et al., 2015). No entanto, quando os frutos avaliados neste experimento foram expostos ao ambiente, a temperatura elevada auxiliou na expressão das infecções latentes antes contidas pela baixa temperatura, e o aumento do período de exposição resultou em maior severidade de podridão parda, conforme o observado no período 3 (Tabela 1). Estes dados corroboram com os resultados encontrados por Moreira e May-de Mio (2009).

Além do fungo fitopatogênico Monilinia fructicola, uma diversidade de outros microrganismos estão presentes em frutos de pessegueiro, mesmo não sendo causadores de doenças, como por exemplo Alternaria, Aspergillus, Aureobasidium, Botrytis, Cladosporium, Fusarium, Giberela, Mucor, Penicillium, Rhizopus, Trichoderma, merecendo destaque na pesquisa do controle biológico (BETTIOL, 1991). Microrganismos que ocorrem naturalmente na superfície das plantas, sem causar doença têm sido normalmente associados a antagonistas de patógenos (MOREIRA e MAY-DE MIO, 2006).

Para o controle de Monilinia fructicola na cultura do pessegueiro, são recomendados tratamentos à base de tebuconazole, enxofre inorgânico, ditiocarbamato, fenilpiridinilamina, oxicloreto de cobre, oxido cuproso, dicarboximida e cloroaromático (MAPA, 2008). Desse modo, o tebuconazole (grupo dos triazóis) faz parte de apenas um dos princípios de controle registrados para essa doença, que sozinho ou associado a outros ingredientes ativos apresenta potencial para controle da podridão parda na floração e pré-colheita do pessegueiro (MAY-DE MIO et al., 2004). Seus resultados positivos foram comprovados, sendo observados 99,86\% de controle para Monilinia fructicola (MACHADO et al., 2005), e $94 \%$ de inibição do crescimento micelial com $100 \mathrm{mg} \mathrm{L}^{-1}$ do ingrediente ativo (MOREIRA, 1999).

Quando avaliado neste experimento, o fungicida tebuconazole apresentou resultados positivos no controle de Monilinia fructicola em pessegueiro, alcançando aproximadamente $38 \%$ de controle em relação à testemunha, na fase de colheita (Tabela 1). O fungicida myclobutanil (triazol) foi avaliado no controle de $M$. fructicola, apresentando apenas $29 \%$ de controle (MOREIRA e MAY-DE MIO, 2009), contudo, fungicidas do grupo químico das guanidinas e das dicarboxamidas apresentam 96 e $43 \%$ de controle, respectivamente. Quando tebuconazole foi testado em associação com fungicidas protetores como mancozebe na produção integrada, demonstrou efeito positivo na manutenção da qualidade fitossanitária (MAY-DE MIO, 2008). 
Nas safras 2002/03 e 2003/04, May-de Mio et al. (2008) testaram dois manejos de produção (convencional e integrada), e verificaram melhor desempenho na produção integrada, com menor número de aplicações e redução da podridão parda. Os mesmos autores relatam que a utilização de ingredientes ativos mais específicos como tebuconazole e iprodione podem ter ocasionado este desempenho. Contudo, atualmente não é recomendado o uso de ingredientes específicos que atuem em um único alvo, devido ao risco potencial de resistência dos microrganismos, como comprovado para fludioxonil (classe fenilpirrol), carbendazim (benzimidazol) e tebuconazole (triazol), em diversos trabalhos (HOLB e SCHNABEL, 2007; LUO et al., 2008; HILY et al., 2011; FU et al., 2017).

A sensibilidade reduzida de $M$. fruticola para o grupo químico dos triazóis (DMIs) e dos benzimidazóis (BZIs) já foi relatada em anos passados por Schnabel et al. (2004), principalmente por atuarem em sítios específicos nos microrganismos. Para o grupo químico das estrobilurinas (QoI), atualmente no Brasil, constatou-se sensibilidade de isolados a azoxistrobina (PRIMIANO et al., 2017). Até o momento, a utilização da resistência genética à podridão parda tem sido limitada pela inexistência de cultivares resistentes (MOREIRA e MAY-DE MIO, 2007). Diante da atual situação da perda de sensibilidade dos patógenos aos fungicidas comumente utilizados, tornou-se necessário aprimorar as técnicas da produção integrada em pêssegos, que tem demonstrado resultados promissores no controle de podridão parda a partir da floração.

As aplicações de fosfito de potássio nas plantas de pessegueiro não apresentaram resultados significativos para o controle de Monilinia fructicola na pré e na pós-colheita, corroborando com os dados encontrados por Sautter et al. (2011), para pêssegos da cultivar Magnum. Contudo, efeitos positivos de sua utilização já foram comprovados no controle de doenças, tanto por sua ação tóxica direta sobre o patógeno em plantas, como indiretamente através da indução de mecanismos de defesa do hospedeiro (OGOSHI et al., 2013). Quando associado fosfito + captam, Moreira et al. (2008), encontrou resultados promissores no controle de Monilinia em pomar de pessegueiro. O fosfito de potássio é considerado uma boa opção para o manejo integrado de doenças pós-colheita, pois além de sua forte ação antimicrobiana, apresenta baixa toxicidade ambiental e menores custos de produção (LOBATO et al., 2011).

Não existem relatos do uso de extrato de boldo no controle de Monilinia fructicola, embora sua eficiência já esteja comprovada para outros microrganismos, como por exemplo, para isolados de Colletotrichum sp. (SILVA et al., 2008), para Alternaria solani (Sorauer) e Fusarium sp. (SARTORI et al., 2013), em condições in vitro. Também em condições controladas, os extratos de cravo e canela apresentaram alto potencial antifúngico no controle de Aspergilus niger (Tiegh) e Eurotium repens (de Bary), reduzindo crescimento micelial e germinação de esporos, este efeito positivo está atrelado à composição destas plantas, sendo, eugenol e cynnamic aldehyde, para cravo e canela, respectivamente (CHALFOUN et al., 2004). Venturoso et al. (2011) testando os mesmos extratos vegetais 
encontraram alta supressão sobre o crescimento micelial de Colletotrichum sp., Cercospora kikuchii, Fusarium sp. e de Phomopsis sp. Para Glomerella cingulata (Stoneman) e Colletotrichum gloesporioides (Penz) o extrato de cravo-da-índia também apresentou resultados satisfatórios (ROZWALKA et al., 2008).

Os efeitos positivos encontrados nestes trabalhos devem-se ao fato de serem realizados em condições controladas, livre de intempéries como chuvas, molhamento foliar, radiação intensa e temperaturas oscilantes, as quais são encontradas em condições de campo. Dessa forma, deve ser levado em consideração que para Monilinia fructicola os extratos vegetais de canela, cravo e boldo ainda não foram testados em pomar de pêssego.

A utilização do controle natural deve ser analisada a longo prazo, pois quando compara-se os resultados num curto período de tempo não é possível identificar superioridade no controle em relação aos químicos. Devido a sua característica de ser biodegradáveis, não prejudicam o meio ambiente, além de não interferir na sensibilidade dos patógenos. Embora apresentem limitações, os produtos naturais apresentam grande potencial na agricultura, pois se trata de produtos com mecanismos diferenciados de controle, por isso necessitam de estudos a longo prazo.

\section{CONCLUSÃO}

Os produtos naturais (extratos vegetais de canela, cravo e boldo) não apresentam influência positiva sobre fungos patogênicos durante a pré e pós-colheita do pessegueiro. Os tratamentos naturais e químicos não afetam os aspectos qualitativos da pós-colheita de frutos de pessegueiro cv. Precocinho.

O tratamento químico com tebuconazole apresenta controle eficiente da podridão parda. Os tratamentos naturais devem ser analisados a longo prazo, sugerindo-se novos estudos.

\section{AGRADECIMENTOS}

À FAPERGS pela concessão da bolsa de iniciação científica à primeira autora.

\section{REFERÊNCIAS BIBLIOGRÁFICAS}

MINISTÉRIO DA AGRICULTURA, PECUÁRIA E ABASTECIMENTO - MAPA. AGROFIT - Sistema de Agrotóxicos Fitossanitários. Coordenação Geral de Agrotóxicos e Afins, 2016. Disponível em: <http://agrofit.agricultura.gov.br/agrofit_cons/principal_agrofit_cons>. Acesso: dia 06 jun. 2016.

Cultura Agronômica, Ilha Solteira, v.27, n.1, p.124-140, 2018 
ARAÚJO, L.; STADNIK, M. J.; BORSATO, L. C.; VALDEBENITO-SANHUEZA, R. M. Fosfito de potássio e ulvana no controle da mancha foliar da gala em macieira. Tropical Plant Pathology, Medford, v. 33, n. 2, p.74-80, 2008.

BETTIOL, W. Seleção de microrganismos antagônicos a fitopatógenos. In: BETTIOL, W. (Ed.). Controle Biológico de Doenças de Plantas. Jaguariúna: EMBRAPA, CNPDA, 1991. p. 223-236.

CAI, J.; CHEN, J.; LU, G.; ZHAO, Y.; TIAN, S.; QIN, G. Control of brown rot on jujube and peach fruits by trisodium phosphate. Postharvest Biology and Technology, v. 99, p.93-98, $2015 . \quad$ Disponível em: <https://www.sciencedirect.com/science/article/pii/S0925521414002373>. Acesso em: 13 mar. 2018.

CASALS, C.; ELMER, P. A. G.; VIÑAS, I.; TEIXIDÓ, N.; SISQUELLA, M.; USALL, J. The combination of curing with either chitosan or Bacillus subtilis CPA-8 to control brown rot infections caused by Monilinia fructicola. Postharvest Biology and Technology, v. 64, n. $1, \quad$ p.126-132, 2012. Disponível em: <https://www.sciencedirect.com/science/article/pii/S0925521411001384>. Acesso em: 13 mar. 2018.

CHALFOUN, S. M.; PEREIRA, M. C.; RESENDE, M. L. V.; ANGÉLICO, C. L.; SILVA, R. A. Effect of powdered spice treatments growth, sporulation and production of aflatoxin by toxigenic fungi. Ciência e Agrotecnologia, Lavras, v. 28, n. 4, p.856-862, 2004.

COELHO, L. R.; LEONEL, S.; CROCOMO, W. B.; LABINAS, A. M. Controle de pragas do pessegueiro através do ensacamento dos frutos. Ciência Agrotecnologia, Lavras, v. 32, n. 6, p.1743-1747, 2008.

CRUZ, C. D. Genes: a software package for analysis in experimental statistics and quantitative genetics. Acta Scientiarum: Agronomy, Maringá, v. 35, n. 3, p.271-276, 2013.

DANNER, M. A.; SASSO, S. A. Z.; MEDEIROS, J. G. S.; MARCHESE, J. A.; MAZARO, S. M. Indução de resistência à podridão parda em pêssegos pelo uso de eliciadores em póscolheita. Pesquisa Agropecuária Brasileira, Brasília, v. 43, n. 7, p.793-799, 2008.

FATTOUCH, S.; CABONI, P.; CORONEO, V.; TUBEROSO, C.; ANGIONI, A.; DESSI, S.; CABRAS, P. Comparative analysis of polyphenolic profiles and antioxidant and antimicrobial activities of tunisian pome fruit pulp and peel aqueous acetone extracts. Journal of agricultural and food chemistry, Easton, v. 56, n. 3, p.1084-1090, 2008.

FU, W.; TIAN, G.; PEI, Q.; GE, X.; TIAN, P. Evaluation of berberine as a natural compound to inhibit peach brown rot pathogen Monilinia fructicola. Crop Protection, v. 91, n. 9 , p.20-26, 2017. Disponível em: <https://www.sciencedirect.com/science/article/pii/S0261219416302526>. Acesso em: 13 mar. 2018.

Cultura Agronômica, Ilha Solteira, v.27, n.1, p.124-140, 2018 
HOLB, I.; SCHNABEL, G. Differential effect of triazoles on mycelial growth and disease measurements of Monilinia fructicola isolates with reduced sensitivity to DMI fungicides. Crop Protection, v. 26, n. 5, p.753-759, 2007. Disponível em: <https://www.sciencedirect.com/science/article/pii/S0261219406001955>. Acesso em: 13 mar. 2018.

HILY, J. M.; CANTOR, S. D.; VILLANI, S. M.; COX, K. D. Caracterização do gene do citocromo b (cyt b) de espécies de Monilinia causando podridão parda de frutos de pedra e de pomácea e sua importância no desenvolvimento de resistência ao QoI. Pest Management Science, v. 67, n. 4, p.385-396, 2011. Disponível em: <http://onlinelibrary.wiley.com/doi/10.1002/ps.2074/full>. Acesso em: 13 mar. 2018.

KESKE, C.; AMORIM, L.; MAY-DE MIO, L. L. Peach brown rot incidence related to pathogen infection at different stages of fruit development in an organic peach production system. Crop Protection, v. 30, n. 7, p.802-806, 2011. Disponível em: <https://www.sciencedirect.com/science/article/pii/S0261219411000949>. Acesso em: 13 mar. 2018.

LURIE, S.; CRISOSTO, C. H. Chilling injury in peach and nectarine. Postharvest Biology and Technology, v. 37, n. 3, p.195-208, 2005. Disponível em: <https://www.sciencedirect.com/science/article/pii/S0925521405000888>. Acesso em: 13 mar. 2018.

LEE, M. H.; BOSTOCK, R. M. Fruit exocarp phenols in relation to quiescence and development of Monilinia fructicola infections in Prunus spp.: A role for cellular redox? Phytopathology, v. 97, n. 3, p.269-277, 2007. Disponível em: <https://apsjournals.apsnet.org/doi/abs/10.1094/PHYTO-97-3-0269> Acesso em: 13 mar. 2018 .

LINS, S. R. O.; OLIVEIRA, S. M. A.; ALEXANDRE, E. R.; SANTOS, A. M. G.; OLIVEIRA, T. A. S. Alternative control of stem-end rot in mango. Summa Phytopathologica, Botucatu, v. 37, n. 3, p.121-126, 2011.

LOBATO, M. C.; MACHINANDIARENA, M. F.; TAMBASCIO, C.; DOSIO, G. A. A.; CALDIZ, D. O.; DALEO, G. R.; ANDREU, A. B.; OLIVIERI, F. P. Effect of foliar applications of phosphite on post-harvest potato tubers. European Journal of Plant Pathology, v. 130, n. 2, p.155-163, 2011. Disponível em: <https://link.springer.com/article/10.1007/s10658-011-9741-2>. Acesso em: 13 mar. 2018.

LUO, C. X.; COX, K. D.; AMIRI, A.; GUIDO, S. Ocorrência e detecção do elemento genético associado à resistência à DMI 'Mona' em Monilinia fructicola. Plant Disease, v. 92, n. 7, p.1099-1103, 2008. Disponível em: <https://www.researchgate.net/profile/Paulo_Lichtemberg/publication/308137334_Resisten cia_de_Monilinia_spp_aos_fungicidas_dos_grupos_dos_inibidores_da_desmetilacao_IDM_ dos_inibidores_da_quinona_externa_IQE_e_dos_metilo_benzimidazol_carbamatos_MBC/li nks/57dadf7e08aeea1959329e41.pdf>. Acesso em: 13 mar. 2018.

Cultura Agronômica, Ilha Solteira, v.27, n.1, p.124-140, 2018 
MARTINS, M. C.; BETTI, J. A.; LEITE, R. M. V. B. C.; LEITE JUNIOR, R. P.; AMORIM, L. Doenças das rosáceas de caroço. In: KIMATI, H.; AMORIM, L.; REZENDE, J. A. M.; BERGAMIM FILHO, A.; CAMARGO, L. E. A. (Ed.). Manual de fitopatologia. 4. ed. São Paulo: Agronômica Ceres, 2005. p. 545-557.

MAY-DE MIO, L. L.; GARRIDO, L.; UENO, B. Doenças de fruteiras de caroço. In: MONTEIRO, L. B.; MAY-DE MIO, L. L.; SERRAT, B. M.; MOTTA, A. C.; CUQUEL, F. L. ed. Fruteiras de caroço: uma visão ecológica. Curitiba: UFPR, 2004. p. 169-221.

MAY-DE MIO, L. L.; MOREIRA, L. M.; MONTEIRO, L. B.; JUSTINIANO JÚNIOR, P. R. Infecção de Monilinia fructicola no período de floração e incidência de podridão-parda em frutos de pessegueiro, em dois sistemas de produção. Tropical Plant Pathology, Brasília, v. 33, n. 3, p.227-234, 2008.

MAZARO, S. M.; DESCHAMPS, C.; MIO, L. L. M.; BIASI, L. A.; GOUVEA, A. D.; SAUTTER, C. K. Comportamento pós-colheita de frutos de morangueiro após a aplicação pré-colheita de quitosana e acibenzolar-S-metil. Revista Brasileira de Fruticultura, Jaboticabal, v. 30, n. 1, p.185-190, 2008.

MACHADO, N. P.; COUTINHO, E. F.; ANTUNES, P. L. Técnicas alternativas no controle de podridões pós-colheita de pêssegos. Pelotas: Embrapa Clima Temperado. 2005. $21 \mathrm{p}$.

MAGUIRE, K. M.; BANKS, N. H.; LANG, A.; GORDON, I. L. Harvest date, cultivar, orchard, and tree effects on water vapor permeance in apples. Journal of the American Society for Horticultural Science, Alexandria, v. 125, n. 1, p.100-104, 2000.

MOREIRA, L. M. Controle químico e biológico de Monilinia fructicola (Wint) Honey e monitoramento de infecções latentes em frutos. Curitiba, 1999. 76 f. Dissertação (Mestrado em Produção Vegetal) - Universidade Federal do Paraná, Curitiba, 1999.

MOREIRA, L. M.; MAY-DE MIO, L. L. Efeito de fungos antagonistas e produtos químicos no controle da podridão parda em pomares de pessegueiro. Floresta, Curitiba, v. 36, n. 2, p.287-293, 2006.

MOREIRA, L. M.; MAY-DE MIO, L. L. Crescimento micelial de Monilinia fructicola e Trichothecium roseum em diferentes temperaturas e sensibilidade do antagonista a fungicidas e fosfitos. Scientia Agraria, Curitiba, v. 8, n. 3, p.337-341, 2007.

MOREIRA, L. L.; MAY-DE MIO, L. L.; VALDEBENITO-SANHUEZA, R. M. Fungos antagonistas e efeito de produtos químicos no controle da podridão parda em pomar de pessegueiro. Summa Phytopathologica, Botucatu, v. 34, n. 3, p.272-276, 2008.

MOREIRA, L. M.; MAY-DE MIO, L. L. Controle da podridão parda do pessegueiro com fungicidas e fosfitos avaliados em pré e pós-colheita. Ciência e agrotecnologia, Lavras, v. 33, n. 1, p.405-411, 2009.

Cultura Agronômica, Ilha Solteira, v.27, n.1, p.124-140, 2018 
NAVA, G. A.; BRACKMANN, A. Efeito do pré-resfriamento e da umidade relativa da câmara sobre a qualidade pós-colheita de pêssegos (Prunus persica (L.) Batsch), cv. 'Chiripá'. Revista Científica Rural, Bagé, v. 6, n. 2, p.153-158, 2001.

OGOSHI, C.; ABREU, M. S. D.; SILVA, B. M. D.; NETO, H. S.; RIBEIRO JÚNIOR, P. M.; RESENDE, M. L. V. D. Potassium phosphite: a promising product in the management of diseases caused by Colletotrichum gloeosporioides in coffee plants. Bioscience Journal, Uberlândia, v. 29, n. 5, p.1558-1565, 2013.

PRIMIANO, I. V.; PEREIRA, W. V.; MORALES, R. G. F.; PERES, N. A.; AMORIM, L.; MAY-DE MIO, L. L. Reduced sensitivity to azoxystrobin of Monilinia fructicola isolates from Brazilian stone fruits is not associated with previously described mutations in the cytochrome b gene. Plant Disease, v. 101, n. 5, p.766-773, 2017. Disponível em: <https://apsjournals.apsnet.org/doi/abs/10.1094/PDIS-09-16-1247-RE>. Acesso em: 13 mar. 2018.

ROZWALKA, L. C.; LIMA, M. L. R. Z. C.; MAY-DE MIO, L. L.; NAKASHIMA, T. Extratos, decoctos e óleos essenciais de plantas medicinais e aromáticas na inibição de Glomerella cingulata e Colletotrichum gloeosporioides de frutos de goiaba. Ciência Rural, Santa Maria, v. 38, n. 2, p.301-307, 2008.

SAUTTER, C. K.; BRACKMANN, A.; ANESE, R. O.; WEBER, A.; RIZZATTI, M. R. Controle da podridão-parda e características físico-químicas de pêssegos 'Magnum'submetidos a tratamentos pós-colheita com elicitores abióticos. Revista Ceres, Viçosa, v. 58, n. 2, p.172-177, 2011.

SARTORI, V. C.; BIONDO, F.; PANSERA, M. R.; SILVA-RIBEIRO, R. T. 13871Atividade biológica de aveloz (Euphorbia tirucalli), boldo (Pneumus boldus) e cânfora (Cinnamomun camphora) sobre Alternaria sp e Fusarium sp. Cadernos de Agroecologia, v. $8, \quad$ n. 2, p.1-5, 2013. Disponível em: <http://revistas.abaagroecologia.org.br/index.php/cad/article/view/13871>. Acesso em: 13 mar. 2018.

SCHNABEL, G.; BRYSON, P. K.; BRIDGES, W. C.; BRANNEN, P. M. Reduced sensitivity in Monilinia fructicola to propiconazole in Georgia and implications for disease management. Plant Disease, v. 88, n. 9, p.1000-1004, 2004. Disponível em: <https://apsjournals.apsnet.org/doi/abs/10.1094/PDIS.2004.88.9.1000>. Acesso em: 13 mar. 2018.

SILVA, M. B.; NICOLI, A.; COSTA, A. S. V.; BRASILEIRO, B. G.; JAMAL, C. M.; SILVA, C. A.; TEIXEIRA, H. Ação antimicrobiana de extratos de plantas medicinais sobre espécies fitopatogênicas de fungos do gênero Colletotrichum. Revista Brasileira de Plantas Medicinais, Paulinia, v. 10, n. 3, p.57-60, 2008.

SIVAKUMAR, D.; BAUTISTA-BAÑOS, S. A review on the use of essential oils for postharvest decay control and maintenance of fruit quality during storage. Crop Protection, v. 64, p.27-37, 2014. Disponível em: 
<https://www.sciencedirect.com/science/article/pii/S0261219414001756>. Acesso em: 13 mar. 2018.

SPADONI, A.; NERI, F.; BERTOLINI, P.; MARI, M. Control of Monilinia rots on fruit naturally infected by hot water treatment in commercial trials. Postharvest biology and technology, v. $86, \quad$ p.280-284, 2013. Disponível em: <https://www.sciencedirect.com/science/article/pii/S0925521413002159>. Acesso em: 13 mar. 2018

TOZZE JÚNIOR, H. J.; FIRMINO, A. C.; FISCHER, I. H.; FURTADO, E. L.; MASSOLA JÚNIOR, N. S. Characterization of Colletotrichum spp. isolates associated with fruit trees in the state of São Paulo. Summa Phytopathologica, Botucatu, v. 41, n. 4, p.270-280, 2015.

VENTUROSO, L. R.; BACCHI, L. M. A.; GAVASSONI, W. L.; CONUS, L. A.; PONTIM, B. C. A.; SOUZA, F. R. Inibição do crescimento in vitro de fitopatógenos sob diferentes concentrações de extratos de plantas medicinais. Arquivos do Instituto Biológico, São Paulo, v. 78, n. 1, p.89-95, 2011.

VICENTE, R.; SALADIE, M.; ROSE, J. K.; LABAVITCH, J. M. A ligação entre o metabolismo da parede celular e o abrandamento da fruta: Olhando para o futuro. Journal of the Science of Food and Agriculture, v. 87, n. 8, p.1435-1448, 2007. Disponível em: <http://onlinelibrary.wiley.com/doi/10.1002/jsfa.2837/full〉. Acesso em: 13 mar. 2018.

VILLARINO, M.; SANDÍN-ESPAÑA, P.; MELGAREJO, P.; DE CAL, A. High chlorogenic and neochlorogenic acid levels in immature peaches reduce Monilinia laxa infection by interfering with fungal melanin biosynthesis. Journal of Agricultural and Food Chemistry, Easton, v. 59, n. 7, p.3205-3213, 2011.

ZHANG, Y.; ZENG, L.; YANG, J.; ZHENG, X.; YU, T. 6-Benzylaminopurine inhibits growth of Monilinia fructicola and induces defense-related mechanism in peach fruit. Food Chemistry, Easton, v. 187, p.210-217, 2015.

Cultura Agronômica, Ilha Solteira, v.27, n.1, p.124-140, 2018 